\title{
Enfrentamento da internação hospitalar do paciente adulto pelo familiar cuidador
}

Facing the hospitalization of the adult patient by the family caregiver

Frente a la hospitalización del paciente adulto por el cuidador familiar

\section{Caroline Passos ArrudaI, Giovana Calcagno Gomes ${ }^{I I}$, Manoela Cunha Nicoletti"II, Vanessa da Silva Tarouco ${ }^{\mathrm{IV}}$, Cintia Camila Santos de Souza ${ }^{\mathrm{v}}$ Aline Ney Grehs ${ }^{\mathrm{vI}}$}

\begin{abstract}
Resumo: Objetivo: conhecer como o familiar cuidador enfrenta a internação hospitalar do paciente adulto. Método: pesquisa descritiva e exploratória de cunho qualitativo realizada em abril de 2018 em um Hospital Universitário no sul do Brasil. Participaram 20 familiares acompanhantes. Os dados foram coletados por meio de entrevistas e submetidos à Análise Temática. Resultados: os sentimentos apresentados em relação à internação foram de preocupação, ansiedade, medo da morte e tranquilidade. A família elegeu um dos familiares para ser o principal cuidador ou realizou revezamento. Às vezes o cuidador necessitou pedir dispensa do trabalho para cuidar, outros familiares se dedicaram aos aspectos do viver fora do hospital e a família expandiu-se. Considerações Finais: é importante direcionar a assistência ao familiar cuidador, contemplando a humanização, a criação de vínculo e a comunicação, pois ele é o maior aliado dos membros da equipe de saúde no hospital.
\end{abstract}

Descritores: Cuidadores; Família; Hospitais; Pacientes; Enfermagem

Abstract: Objective: know how the family caregiver faces the hospitalization of the adult patient. Method: descriptive and exploratory qualitative research conducted in April 2018 at a University Hospital in southern Brazil. Twenty family caregiver participated. Data were collected through interviews and subjected to Thematic Analysis. Results: The feelings presented regarding hospitalization were worry, anxiety, fear of death and tranquility. The family elected one of the family members to be the primary caregiver or took turns. Sometimes the caregiver needed to take time off to care, other family members dedicated themselves to aspects of living outside the hospital, and the family expanded. Final Considerations: It is important to direct care to the family caregiver,

\footnotetext{
${ }^{\text {I }}$ Enfermeira. Universidade Federal do Rio Grande. Rio Grande/RS. Brasil. carolparruda@gmail.com. https://orcid.org/0000-0001-8475-1474

${ }^{\text {II }}$ Docente da Escola de Enfermagem. Doutora em Enfermagem. Universidade Federal do Rio Grande. Rio Grande/RS. Brasil. giovanacalcagno@furg.br. https://orcid.org/0000-0002-2464-1537

IIIEnfermeira. Universidade Federal do Rio Grande. Rio Grande/RS. Brasil. manoela.nicolettii@gmail.com. https://orcid.org/0000-0001-9774-8733

${ }^{\mathrm{IV}}$ Enfermeira. Universidade Federal do Rio Grande. Rio Grande/RS. Brasil. vanessa.tarouco_94@hotmail.com. https://orcid.org/0000-0003-04546732 .

${ }^{\mathrm{v}}$ Enfermeira. Residente do programa Residência Multiprofissional em Saúde da Família. Universidade Federal do Rio Grande. Rio Grande/RS. Brasil. cintiacamilacosta@gmail.com. https://orcid.org/0000-0002-9033-9918.

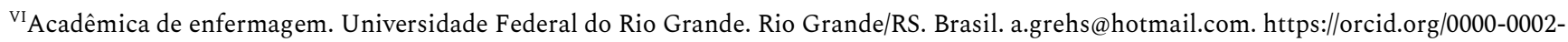
0570-9583
} 
contemplating humanization, bonding and communication, as he is the greatest ally of the health team members in the hospital.

Descriptors: Caregivers; Family; Hospital; Patients; Nursing

Resumen: Objetivo: saber cómo el cuidador familiar enfrenta la hospitalización del paciente adulto. Método: investigación cualitativa descriptiva y exploratoria realizada en abril de 2018 en un Hospital Universitario en el sur de Brasil. Participaron veinte familiares acompañantes. Los datos fueron recolectados a través de entrevistas y sometidos a análisis temático. Resultados: Los sentimientos presentados con respecto a la hospitalización fueron preocupación, ansiedad, miedo a la muerte y tranquilidad. La familia eligió a uno de los miembros de la familia para ser el cuidador principal o se turnó. A veces, el cuidador necesitaba tomarse un tiempo libre para cuidar, otros miembros de la familia se dedicaron a aspectos de la vida fuera del hospital y la familia se expandió. Consideraciones finales: es importante dirigir la atención al cuidador familiar, contemplando la humanización, el vínculo y la comunicación, porque él es el mejor aliado de los miembros del equipo de salud en el hospital.

Descriptores: Cuidadores; Familia; Hospitales; Pacientes; Enfermería

\section{Introdução}

Os hospitais se tornaram espaços para examinar, investigar e tratar as condições de saúde da população, ocupando lugar central no sistema de saúde. Durante o fazer da equipe de enfermagem no hospital ocorrem convivências diárias, principalmente, com os familiares cuidadores, que geralmente, acompanham os pacientes ao longo da internação. A internação hospitalar pode apresentar-se como fonte de estresse para a família, havendo a necessidade de um período de adaptação no qual o enfermeiro e sua equipe devem prover acolhimento, auxílio e segurança ao paciente e sua família. ${ }^{1}$

No âmbito hospitalar percebe-se a desestruturação da rotina de vida do familiar cuidador, visto que sua atenção se encontra centrada na possibilidade de recuperação ou risco de vida do seu familiar internado. Nesse sentido, esta mudança em sua rotina exige que o cuidador adapte sua vida social e profissional para estar próximo de seu parente, permitindo acompanhar seu quadro clínico de perto. ${ }^{2}$

Com objetivo de auxiliar o familiar na vivência deste momento, de forma menos traumática, a comunicação e o vínculo podem ser ferramentas importantes entre os 
profissionais da saúde e o familiar cuidador. A comunicação possibilita compreender as características, necessidades e expectativas da família para direcionar a assistência, de modo que as condutas realizadas sejam voltadas à realidade de cada família. Estudo que objetivou identificar e descrever as percepções de familiares sobre o cuidado ao paciente hospitalizado sugeriu que os profissionais, especialmente aqueles que atuam no cenário de internação, devem realizar intervenções que visem minimizar os impactos da tarefa de cuidar e, consequentemente, a melhora da qualidade de vida dos familiares cuidadores no ambiente hospitalar..$^{3-4}$

O período da hospitalização pode configurar-se como um evento desestruturante e traumático para a família capaz de gerar sentimentos como medo e insegurança. Por esse motivo, compreende-se que o enfermeiro e sua equipe devem oferecer apoio e segurança ao paciente e sua família, orientando-os como compartilhar o cuidado diário ao paciente. ${ }^{5}$

Durante o período de internação, os familiares cuidadores podem sentir-se esgotados física e emocionalmente. A rotina da unidade de internação, com procedimentos invasivos e repleta de tecnologias desconhecidas pode resultar em sentimentos conflitantes para a família. Estudo que investigou as percepções e sentimentos expressos por familiares cuidadores no hospital apontou que os mesmos referiram insegurança, medo, ansiedade, preocupação, sentimentos de privação da liberdade e ao mesmo tempo, gratidão pela assistência, conforto, segurança e proximidade para o controle do cuidado. ${ }^{6}$ Nesse sentido, é necessário o apoio afetivo e intervenções adequadas da equipe de enfermagem para que este momento seja menos assustador.

Ao interagir com a equipe de enfermagem a família busca compartilhar sentimentos e percepções diante da vida e da fragilidade de seu familiar internado. Torna-se importante a presença de um profissional que esclareça suas dúvidas e se mostre disponível, fortalecendo a estrutura familiar, criando com essa um vínculo afetivo e de respeito, contribuindo para uma relação de bem-estar no ambiente hospitalar. ${ }^{7}$ 
Enfrentamento da internação hospitalar do paciente adulto pelo familiar cuidador $\mid 4$

O papel do enfermeiro frente ao familiar cuidador consiste em propor estratégias direcionadas a sanar suas dificuldades, facilitando seu processo de cuidado no hospital, mas para isso é necessário conhecer suas vivências no âmbito hospitalar. Nesse sentido, a questão do estudo foi: como o familiar cuidador enfrenta a internação hospitalar do paciente adulto? A partir dessa, objetivou-se conhecer como o familiar cuidador enfrenta a internação hospitalar do paciente adulto. Acredita-se que este conhecimento poderá subsidiar o trabalho da enfermagem junto ao familiar do paciente adulto, auxiliando-o na transição do seu papel de cuidador no hospital.

\section{Método}

Realizou-se uma pesquisa descritiva e exploratória de cunho qualitativo. A pesquisa qualitativa lida com o universo de significados, crenças, aspirações, motivos, valores e atitudes. ${ }^{8}$ Ela permite que o autor se envolva diretamente na situação e possibilita observar os agentes no seu cotidiano, convivendo e interagindo socialmente com estes. A pesquisa descritiva tem como objetivo a descrição das características de determinada população ou fenômeno. ${ }^{9}$

O estudo foi realizado nas Unidades de Clínica Médica (UCM) e Clínica Cirúrgica (UCC) de um Hospital Universitário do sul do Brasil (HU). Além da assistência à saúde o HU desenvolve ações de ensino, pesquisa e extensão. É um hospital que atende pacientes conveniados pelo Sistema Único de Saúde (SUS) e constitui-se em um campo de atividades práticas para acadêmicos de enfermagem, medicina, psicologia e educação física incluindo a Residência Integrada Multiprofissional Hospitalar com ênfase na atenção à saúde cardiometabólica do adulto (RIMHAS).

A UCM possui 50 leitos destinados a pacientes internados com intercorrências clínicas, distribuídos em 12 enfermarias, sendo sete leitos de isolamento. A UCC possui 29 leitos destinados a pacientes internados com intercorrências cirúrgicas, distribuídos em oito enfermarias, sendo dois isolamentos. 
Participaram do estudo 20 familiares cuidadores de pacientes internados nas referidas unidades em abril de 2018. Os critérios de inclusão foram: acompanhar o paciente durante sua internação, prestar cuidados contínuos na Unidade e ter dezoito anos ou mais. Foram excluídos familiares que apenas realizaram visitas aos pacientes nos setores. Após orientados acerca dos objetivos e metodologia do estudo, os familiares que aceitaram participar assinaram o Termo de Consentimento Livre e Esclarecido em duas vias.

O número de participantes foi delimitado pela saturação de dados, ou seja, o número de pessoas que integraram o estudo foi determinado no momento em que não surgiram novas informações e as respostas começarem a se repetir. Uma amostra qualitativa ideal é a que reflete, em quantidade e intensidade, as múltiplas dimensões de determinado fenômeno e busca a qualidade das ações e das interações em todo o decorrer do processo. ${ }^{10}$ Após convite não houve recusas em participar do estudo.

Os dados foram coletados pelas pesquisadoras por meio de entrevistas semiestruturadas gravadas em MP3 e transcritas para análise. Tiveram duração média de 45 minutos. Foram realizadas na sala de procedimentos de cada uma das Unidades por garantir privacidade aos participantes. Foram questionados acerca de como enfrentavam a internação hospitalar de seu familiar.

A Análise Temática dos dados foi operacionalizada a partir da Pré-análise, na qual se realizou a leitura flutuante dos dados, o agrupamento das falas e elaboração das unidades de registro. Foi realizada também a exploração do material, na qual se realizou a codificação dos dados e atribuição de códigos aos núcleos de sentido que representaram o conteúdo expresso nas falas. Esses foram agregados em unidades, codificados e organizados em categorias. Por fim foi realizado o tratamento dos resultados obtidos e interpretação, na qual as falas mais significativas foram discutidas a partir de autores para dar suporte à analise. ${ }^{8}$

Foram seguidos os aspectos éticos de acordo com a resolução 466/2012 que rege as pesquisas com seres humanos. O projeto recebeu parecer de aprovação do Comitê de Ética em 
Pesquisa na Área de Saúde (CEPAS/FURG) sob número 30/2018. As falas dos participantes foram identificadas pela letra $\mathrm{F}$ seguida do número da entrevista, com vistas a garantir o seu anonimato.

\section{Resultados}

A seguir apresenta-se a caracterização dos participantes do estudo e os temas gerados a partir da análise dos dados. Participaram do estudo 20 familiares acompanhantes de pacientes internados na UCM e UCC do HU, sendo oito da UCC e 12 da UCM. Suas idades variaram entre 28 e 72 anos com uma média de 49,25 anos.

Quanto ao grau de parentesco com o paciente sete eram filhas, três eram irmãs, três eram maridos, três eram esposas, duas eram amigas, uma tia e um filho. Com relação ao grau de estudo, sete possuíam ensino fundamental incompleto, seis possuíam ensino médio completo, quatro eram analfabetos, dois possuíam ensino superior completo e um possuía ensino superior incompleto. Quanto ao número de filhos, dois familiares não apresentavam filhos, no entanto os demais possuíam entre um e seis filhos com uma média de 2,33 filhos. Quanto à idade do paciente internado, esta variou entre 17 e 92 anos, com média de 62,7 anos. Quanto ao tempo de internação, este variou entre um dia e três meses.

\section{Sentimentos apresentados pelos familiares em relação à internação}

No âmbito da internação hospitalar de um paciente adulto, o familiar cuidador passa a apresentar necessidades emocionais relativas à sua transição para o papel de cuidador. A necessidade de cuidar no hospital, ambiente diverso ao domicílio, pode gerar diversos sentimentos. Um dos sentimentos apresentados pelo familiar cuidador em relação à 
hospitalização foi preocupação em cuidar do familiar adequadamente. Referiram sentir tristeza devido o sofrimento e a dor apresentados pelo seu familiar e pelos outros pacientes internados.

Principalmente preocupação, a gente é casado há tanto tempo, é sempre eu e ele só. Fico preocupada porque se acontecer algo nem força eu tenho para carregá-lo. (F16)

Sentimentos de tristeza de ver o sofrimento, não só dele, como de todos os pacientes que a gente vê aqui dentro. Um sofrimento. (F15)

Fica difícil, ficamos tristes, porque ele está sofrendo e com dor. (F2)

Apresentaram medo da morte do seu familiar. Apesar da esperança na recuperação, a cada nova hospitalização parecia que o desfecho morte ficava mais próximo, tendo em vista o é agravamento do quadro clínico do seu familiar e a sua debilidade. A morte é vista como um evento assustador, configurando-se em um medo universal.

Senti muito medo, nervosa, agoniada e muito medo. Ela está velhinha, mas ninguém quer perder. (F9)

Tivemos muito medo. Muito. Ela teve câncer no pulmão há mais de dois anos e o ano passado teve aquela infecção, quase se foi. Agora já se tinha o medo que fosse acontecer o pior. (F3)

A internação hospitalar pode submeter o familiar ao desespero e desconforto. Um dos familiares referiu acompanhar a hospitalização por morar distante e essa promover a desestruturação familiar.

Desespero. Dois meses aqui é brabo. Moro na ilha, fica difícil. (F19)

Desconforto porque não somos daqui, é tudo dificultoso porque tu não estás na tua cidade, a familia fica longe, parei de trabalhar e para pegar um atestado não é fácil também, porque tenho que chegar com o atestado 48 horas lá e eu estou aqui. (F10) 
Enfrentamento da internação hospitalar do paciente adulto pelo familiar cuidador | 8

A pena surge pela observação da fragilidade e das limitações impostas pela hospitalização. O familiar internado passa a ser dependente de seus cuidadores.

Ah, eu tenho pena, porque ela sempre foi muito ágil, fazia as coisas dela sozinha. Ela mora nos fundos da casa da minha mãe. Ela não é casada, então mora sozinha, sozinha mesmo. Ela sempre gostou de fazer as coisas, pagar as contas dela e depois que veio para cá não consegue fazer mais nada. Depende da gente para tudo. Acaba sendo complicado. Não tenho mais o que fazer, faço o que posso. (F8)

Os familiares acompanhantes referiram ficar nervosos quanto à internação. A cuidadora de uma paciente que internou com pneumonia referiu que o nervosismo se deve ao desconhecimento acerca do que vai acontecer no hospital. Outra cuidadora de uma paciente que internou para uma cirurgia de colectomia referiu que o nervosismo se deve ao fato de que toda cirurgia possui riscos.

Minha filha meio que chorou. A gente fica nervosa com o que vai acontecer. Eu disse para não chorar [...] vai dar tudo certo. (F20)

Bem, fiquei um pouco nervosa. Toda cirurgia submete o paciente a riscos. (F13)

A ansiedade surgiu pela não estabilização do quadro clínico do familiar internado. A piora do quadro clínico torna o paciente vulnerável e incapaz de realizar as atividades de vida diária, tornando-se dependente do cuidador.

[...] nós estamos ansiosos, a pressão dele até subiu ontem [...]. (F14)

[...] ansiedade, ansiedade porque quero ir embora e ele está cada dia pior

[...] não consegue falar, caminhar. Cada dia mais dependente. (F5) 
A aceitação da hospitalização se deu pela percepção da necessidade de seu familiar receber tratamento que no hospital está disponível. Sentem-se aliviados pela hospitalização, por reconhecê-la como importante para a melhora do seu familiar.

[...] ruim, mas tenho que aceitar, fazer o que. (F12)

[...] tem que lidar. Infelizmente, eu sou cuidadora de idoso. Isso aí, a gente vai passar com todos. (F18)

Sentimentos como amor, carinho e respeito são relatados devido à relação existente entre o cuidador e o paciente internado. O cuidador sente-se responsável em acompanhar o paciente no hospital, promovendo-lhe conforto e assistência.

Ela não tem filhos, parentes próximos, nem marido. Sou amiga dela há anos. A gente trabalhava de cuidadoras juntas. Éramos cinco e ela era a chefe. Depois ela saiu e eu fiquei de responsável. A gente se apega mais do que deve. Eu me sinto responsável e com o dia-a-dia a gente se apega. Tem que ter um sentimento para fazer isso. Eu faço porque gosto. Fazer com amor, carinho e respeito. $(\mathrm{F} 6)$

\section{Formas de organização da família para o cuidado no hospital}

Frente à necessidade da internação hospitalar a família elege um dos familiares para ser o principal cuidador no hospital. A esse compete acompanhar seu familiar quase que o tempo todo, sendo a fonte de informações acerca da internação para os outros membros da família. Esse acompanhante abandona sua vida fora do hospital, casa, família e filhos para dedicar-se integralmente ao cuidado no hospital.

[...] abandonei minha vida. Pela mãe a gente faz isso. (F18)

[...] larguei marido, larguei a casa, larguei tudo para estar com ele e vou continuar com ele até o final. (F15) 
Enfrentamento da internação hospitalar do paciente adulto pelo familiar cuidador $\mid 10$

Outra forma de organização apresentada é o revezamento entre os familiares para realizar o cuidado nas 24 horas do dia. Tal forma de organização possibilita que vários familiares contribuam com o cuidado não sobrecarregando apenas uma pessoa.

[...] eu me revezo com a minha irmã, ela vem de noite e eu venho de dia.

Geralmente, eu fico durante o dia e alguém vem pela noite, quando não tem eu fico direto com ela. (F4)

Quando a internação se dá de forma eletiva há um período para a família se organizar e disponibilizar o cuidado no hospital. Nesse tempo, conseguiram decidir como seria o cuidado dos filhos e obtiveram licença do trabalho.

É que foi tudo muito rápido, nos ligaram no domingo para ela internar, aí ela já veio, já fez a cirurgia e a gente já estava voltando para casa. Minha mãe ficou com o nosso filho para eu ficar aqui com ela. (F17)

A gente já sabia que ele teria que ficar aqui, então já nos programamos. Como é só eu e ele, e eu sou aposentada, eu vim para cá. Ele internou ontem, então ainda estamos nos organizando, mas eu vou ficar todo o dia e os filho à noite. (F16)

Em algumas situações a organização para o cuidado no hospital é difícil, pois o familiar cuidador necessita pedir dispensa ao trabalho ou apresentam problemas de saúde incompatíveis com a assistência hospitalar ao seu familiar.

Foi difícil, pois tive que pedir dispensa do serviço. A casa está toda desorganizada, está sendo difícil. (F11)

Tive que largar o emprego, porque eu tenho um problema de saúde e sou aposentada. Então está difícil estar aqui no hospital. (F15) 
Enquanto o familiar cuida do paciente hospitalizado outros familiares se dedicam ao cuidado dos outros aspectos do viver como, por exemplo, cuidar das crianças que ficaram em casa ou de outros familiares que também necessitam ser cuidados.

[...] Um dos filhos a pegou no colo, botou no carro e trouxe. Organizamos as coisas e viemos para o hospital. Os guris nos ajudam muito, ajudam a cuidar do guri que é paralítico, colocam na cadeira, dão banho, por isso achamos melhor ela vir para cá. (F9)

\section{Rede de apoio social da família para o cuidado no hospital}

A principal fonte de apoio para o cuidador é a família nuclear. A partir do estudo, verificou-se que irmãos, filhos e companheiros são os que se dedicam maior parte do tempo para o cuidado do paciente hospitalizado.

$\grave{A} s$ vezes minhas irmãs, quando podem me auxiliam. Às vezes, eu pago alguém para me ajudar. Mas, por enquanto, só tem eu mesmo. (F18)

Nossos filhos trabalham, mas são eles que ajudam. Eu durante o dia e eles a noite. (F16)

Quando não há no núcleo familiar um cuidador disponível para cuidar durante a hospitalização esse acompanhante surge da família expandida. Outros familiares se organizam para dar conta dessa necessidade, mantendo a identidade familiar. Verificou-se que sobrinhos, netos, cunhados foram os que mais proporcionam assistência no cuidado.

Minha filha disse que ela não queria nem que falasse que ela ia operar. [...] Aí eu vim ajudar porque é uma responsabilidade e minha guria tem só 20 anos. Ela é uma criança para ficar sozinha, por isso mesmo que ela decidiu avisar. [...] porque ela pensou que não ia aguentar ficar sozinha com a tia no hospital. (F20) 
Eu e a neta dela cuidamos dela. (F3)

Em alguns casos verificou-se a ausência de redes de apoio para o cuidador central, levando a esses mudarem a rotina das suas vidas, permanecendo em tempo integral no cuidado com o paciente hospitalizado.

Não. Só eu. Só eu e Deus. (F19)

Não, fico sempre eu. (F13)

Quando não há no núcleo familiar nem na família expandida pessoas disponíveis para o cuidado surgem os amigos para auxiliar nessa tarefa, configurando a família anaparental. Pessoas que não possuem laços consanguíneos se aproximam em momentos de necessidade por afinidades construídas ao longo da vida. O suporte desempenha uma função decisiva na adaptação e no exercício do papel de cuidador(a) e contar com alguém para desabafar e obter o reconhecimento pelo esforço do cuidar por parte de amigos apresenta-se muito importante para o cuidador.

[...] sou a única que cuida dela. Ela recusa outra pessoa cuidando e como consegue se levantar, fazer tudo sozinha, acaba não precisando. Uma amiga minha me ajuda. Fica um pouco de tarde para eu ir em casa. (F7)

Como ela era sozinha, a gente já sabia que uma hora ou outra ela ia precisar de ajuda. Tentei organizar meus compromissos e passar aqui cuidando dela. É minha dinda, como se fosse mãe. No geral é muito tranquilo. (F8)

\section{Discussão}

A hospitalização de um dos membros da família causa uma desestruturação familiar, as adversidades interferem no equilíbrio familiar e em sua dinâmica, fazendo com que ela tente se reorganizar para manter o equilíbrio. ${ }^{11}$ Essa reorganização geralmente é acompanhada de 
sofrimento e conflitos, ocorre à abdicação de si para o cuidado do outro e alguns cuidadores interrompem a cotidianidade de sua vida para acompanhar o processo de internação. ${ }^{12}$

Quanto aos sentimentos apresentados pelos familiares em relação à internação, pode-se observar: insegurança, medo, ansiedade, preocupação, sentimentos de tristeza, e ao mesmo tempo, gratidão pela assistência prestada e alívio diante da hospitalização por reconhecê-la como importante para melhora de seu familiar. Tais sentimentos mostram a necessidade de o familiar cuidador obter ajuda frente ao cuidado no hospital. É preciso que expresse seus sentimentos, minimizando suas dúvidas e medos quanto ao futuro. ${ }^{13} \mathrm{Em}$ estudo com familiares cuidadores no hospital esses salientaram que a transição para o papel de cuidador(a) pode se apresentar como um momento inesperado e desconhecido, gerando sentimentos intensos. ${ }^{14}$

A hospitalização constitui-se em um evento estressor e desestabiliza física e emocionalmente toda a família. Os familiares cuidadores podem preocupar-se se estão cuidando do familiar de forma adequada. Podem sentir-se tristes devido o sofrimento e a dor apresentados pelo paciente e ter medo da sua morte ${ }^{.15}$

Outro sentimento presente é a pena. A pena surge pela observação da fragilidade e das limitações impostas pela hospitalização. O familiar internado passa a ser dependente de seus cuidadores. Sentem-se ansiosos pela não estabilização do quadro clínico do familiar. Sua situação de vulnerabilidade e sua incapacidade de manter as habilidades físicas e mentais necessárias para uma vida independente, podem se agravar, gerando ansiedade. ${ }^{3}$

Esta vivência acarreta em aspectos positivos e negativos no âmbito hospitalar. Os negativos estão relacionados às alterações em sua rotina diária, o cansaço físico e emocional e, muitas vezes, problemas financeiros. ${ }^{16} \mathrm{Um}$ estudo realizado nos Estados Unidos da América com 488 famílias apontou que o envolvimento da família no processo de cuidado aos parentes 
Enfrentamento da internação hospitalar do paciente adulto pelo familiar cuidador | 14

com dependência teve como consequência a sobrecarga física, emocional e psicológica, indicando sintomas depressivos. ${ }^{17}$

Porém, por outro lado, os cuidadores sentem satisfação por poder ajudar seus familiares. ${ }^{16}$ A aceitação da hospitalização pode dar-se pela percepção da necessidade de seu familiar receber tratamento que no hospital está disponível e verificar que o mesmo continua a receber amor e carinho e ser tratado com respeito.

A partir do momento em que a família recebe a notícia da necessidade da internação de seu familiar, é preciso que a mesma se reorganize para poder cuidá-lo. E, nesse contexto, alguns familiares relataram abandonar sua vida social para dedicar-se integralmente ao cuidado no hospital, realizam também revezamento de familiares afim de não sobrecarregar apenas um cuidador.

O paciente geralmente necessita de um acompanhante durante a sua internação hospitalar quando esta se dá por meio de um agravo da doença crônica, para a realização de uma cirurgia eletiva ou devido a uma emergência. Os períodos de agudizações são marcados por frequentes internações e consultas com profissionais especialistas. De tal maneira que quando os sintomas diminuem de intensidade, permite que a família se sinta estável. Contudo, há situações emergenciais em que a rotina familiar se altera de maneira abrupta e progressiva, e o familiar deve organizar-se para prestar constantemente cuidados ao paciente. ${ }^{18}$

A família elege um dos familiares para ser o principal cuidador no hospital. Esse acompanhante, geralmente, abandona sua vida, casa, família e filhos para dedicar-se integralmente ao cuidado no hospital. A família, historicamente, sempre desempenhou papel de proteção social de seus membros, sendo a mulher o principal agente nesse processo. ${ }^{19}$ 
Outra forma de organização apresentada é o revezamento entre os familiares para realizar o cuidado nas 24 horas do dia. Enquanto o familiar cuida do paciente hospitalizado outros familiares se dedicam ao cuidado dos outros aspectos do viver. Estudo que objetivou conhecer e analisar apercepção dos cuidadores sobre a experiência de cuidar dos familiares no contexto da hospitalização apontou desgaste emocional e sobrecarga física dos cuidadores decorrente do acompanhamento do familiar na hospitalização. ${ }^{20}$

Quanto à rede de apoio social da família para o cuidado no âmbito hospitalar, verificou-se a presença de filhos, irmãos e netos como principais acompanhantes. A família nuclear apresenta-se como a principal cuidadora. Mesmo diante das transformações societárias o modelo de bem-estar, tem a centralização e supervalorização da família nuclear. ${ }^{21}$

No entanto, chama a atenção que em alguns momentos estes familiares não conseguem dar conta do cuidado e alguns familiares mais distantes agregam-se garantindo esta assistência. As instituições incentivam e promovem a aproximação da família durante o período de internação do paciente e pode-se dizer que esse acompanhamento não é uma boa ação realizada pelos hospitais, mas sim uma necessidade de contribuir na terapêutica do paciente, potencializando sua melhora e oferecendo conforto e suporte emocional neste momento crítico de sua vida. ${ }^{21-22}$

O papel dos profissionais de saúde é determinante, no sentido de ajudar os familiares cuidadores e os pacientes a lidar com esta nova realidade. Faz se necessário ter uma pessoa conhecedora da situação e um profissional com quem se pode contar. ${ }^{23}$ Conhecer as preferências dos cuidadores familiares fornece subsídios para o enfermeiro planejar intervenções educativas que visem ao ensino de forma realista e em consonância com as preferências desta clientela. ${ }^{22} \mathrm{E}$ evidente o papel orientador dos profissionais de enfermagem, sendo o diálogo uma fonte de reflexão e aquisição de saberes. ${ }^{24}$ 


\section{Considerações finais}

O estudo possibilitou conhecer como o familiar cuidador enfrenta a internação hospitalar do paciente adulto. Neste sentido, foram expressos sentimentos de preocupação, ansiedade pela carência de informação acerca da possibilidade de alta, medo da morte e tranquilidade pelo seu familiar estar sob cuidados da equipe. Estes sentimentos dos familiares cuidadores frente à internação hospitalar certificam a importância da organização destes para a prestação integral dos cuidados. Na organização do cuidado faz-se necessário a divisão de tarefas e o revezamento diário, reduzindo a sobrecarga física e emocional. A rede de apoio social da família é a família nuclear, e no momento que esta não consegue dar conta do cuidado, amigos e familiares mais distantes também contribuam, expandindo sua rede de apoio diante do cuidado hospitalar.

Esta pesquisa teve como limitação retratar um contexto específico do cuidado familiar em UCM e UCC de uma instituição do sul do país. Porém, acredita-se que este trabalho possa contribuir para a implementação de novas pesquisas que foquem o cuidado familiar no hospital, pois isto pode incentivar a realização de um cuidado de saúde ampliado, focado não apenas no paciente, cuidando também de quem cuida.

A presença do familiar cuidador no hospital favorece a melhora do paciente, no entanto, também pode ocasionar a exposição desse a situações complexas, de fragilidade. É preciso maior visibilidade desse familiar acompanhante para além das demandas de cuidado. É preciso que a equipe de enfermagem o perceba como alguém também a ser cuidado e potencializado para cuidar, ressignificando sua presença no contexto do hospital.

Concluiu-se como importante conhecer as características, necessidades e expectativas da família, para prestar uma assistência mais direcionada, adequando a condutas à realidade de cada família, a fim de proporcionar uma assistência de qualidade, contemplando a humanização, 
a criação de vínculo e a comunicação, pois ele é a pessoa que está em contato mais próximo com o paciente e deve ser o maior aliado dos membros da equipe de saúde.

\section{Referências}

1. Hosseinian M, Ajorpaz NM, Manesh SE. Mothers' satisfaction with two systems of providing care to their hospitalized children. Iran Red Crescent Med J [Internet]. 2015 [acesso em 2018 abr 28];17(02):105663. Disponível em: https://www.ncbi.nlm.nih.gov/pmc/articles/PMC4376982/

2. Vieira JM, Matos KAP, Andrade-Barbosa TL, Xavier-Gomes LM. Sentimentos vivenciados por familiares de pacientes internados no centro de terapia intensiva adulto. Rev Cubana Enferm [Internet]. 2013 [acesso em 2018 abr 28];29(01):18-28. Disponível em: http://scielo.sld.cu/scielo.php?script=sci_arttext\&pid=S0864-03192013000100004

3. Cabral BPAL, Nunes CMP. Percepções do cuidador familiar sobre o cuidado. Rev Ter Ocup [Internet]. 2015 jan-abr [acesso em 2018 abr 29];26(1):118-27. Disponível em: http://www.revistas.usp.br/rto/article/view/79939/96384

4. Fernandes CS, Angelo M. Family caregivers: what do they need? An integrative review. Rev Esc Enferm USP [Internet]. 2016;50(4):672-8. Disponível em: http://www.scielo.br/scielo.php?script=sci_arttext\&pid=S0080-62342016000400675

5. Nielsen AH, Egerod I, Hansen TB, Angel S. Intensive care unit diaries: developing a shared story strengthens relationships between critically ill patients and their relatives: A hermeneuticphenomenological study. Int J Nurs Stud [Internet]. 2019 [acesso em 2018 maio 29];92:90-6. Disponível em: https://www.ncbi.nlm.nih.gov/pubmed/30753929

6. Machado BM, Dahdah DF, Kebbe LM. Cuidadores de familiares com doenças crônicas: estratégias de enfrentamento utilizadas no cotidiano. Cad Bras Ter Ocup [Internet]. 2018 [acesso em 2018 maio 29];26(2):299-313. Disponível

em:

http://www.cadernosdeterapiaocupacional.ufscar.br/index.php/cadernos/article/view/1979

7. Rodrigues PF, Amador DD, Silva KL, Reichert APS, Collet N. Interaction between the nursing staff and family from the family's perspective. Esc Anna Nery Rev Enferm [Internet]. 2013 [acesso em 2018 abr 29];17(4):781-7. Disponível em: http://www.scielo.br/scielo.php?script=sci_arttext\&pid=S141481452013000400781

8. Minayo MCS. O desafio do conhecimento: pesquisa qualitativa em saúde. 12ª ed. São Paulo: Hucitec; 2010.

9. Gil AC. Como delinear uma pesquisa bibliográfica. 4ª ed. São Paulo: Atlas; 2006. 
10. Minayo MCS. Amostragem e saturação em pesquisa qualitativa: consensos e controvérsias. Rev Pesqui Qual [Internet]. 2017 [acesso em 2018 abr 30];5(7):01-12. Disponível em: https://editora.sepq.org.br/index.php/rpq/article/view/82/59

11. Rodríguez-Sánchez E, Pérez-Peñaranda A, Losada-Baltar A, Pérez-Arechaederra D, Gómez-Marcos MA, Patino-Alonso MC, et al. Relationships between quality of life and family function in caregiver. BMC Fam Pract [Internet]. 2011 [acesso em 2018 abr 30];12(19):70-80. Disponível em: https://www.ncbi.nlm.nih.gov/pmc/articles/PMC3089776/\#__ffn_sectitle

12. Passos SSS, Pereira Á, Nitschke RG. Cotidiano do familiar acompanhante durante a hospitalização de um membro da família. Acta Paul Enferm [Internet]. 2015 [acesso em 2018 maio 05];28(6):539-45. Disponível em: http://www.scielo.br/scielo.php?pid=S010321002015000600539\&script=sci_abstract\&tlng=pt

13. Tsai P-C, Yip P-K, Tai JJ, Lou M-F. Needs of family caregivers of stroke patients: a longitudinal study of caregivers' perspectives. Patient Prefer Adherence [Internet]. 2015 [acesso em 2018 maio 06];9:449-57. Disponível em: https://www.ncbi.nlm.nih.gov/pmc/articles/PMC4370911/

14. Oliveira BC, Garanhani ML, Garanhani MR. Caregivers of people with stroke: needs, feelings and guidelines provided. Acta Paul Enferm [Internet]. 2011 [acesso em 2018 maio 08];24(1):43-9. Disponível em: http://www.scielo.br/pdf/ape/v24n1/en_v24n1a06.pdf

15. Reis LCC, Gabarra, LM, Moré CLOO. As repercussões do processo de internação em UTI adulto na perspectiva de familiares. Temas Psicol [Internet]. 2016 [acesso em 2018 maio 08];24(3):815-28.Disponível em: http://www.redalyc.org/articulo.oa?id=513754280003

16. Lin I-F, Fee H-R, Wu H-S. Negative and positive caregiving experiences: a closer look at the intersection of gender and relationships. Fam Relat [Internet]. 2012 [acesso em 2018 maio 08];61(02):34358. Disponível em: https://www.ncbi.nlm.nih.gov/pmc/articles/PMC3335398/

17. Zimmerman S, Cohen LW, Reed D, Gwyther LP, Washington T, Cagle JG, et al. Comparing families and staff in nursing homes and assisted living: implications for social work practice. J Gerontol Soc Work [Internet]. 2013 [acesso em 2018 maio 05];56(02):535-53. Disponível em: https://www.ncbi.nlm.nih.gov/pmc/articles/PMC3772131

18. Petean E, Araújo LFS, Bellato R. Dimensão espaço-tempo e os atos-atitudes de cuidado na experiência familiar. Rev Pesqui Cuid Fundam [Internet]. 2016 [acesso em 2018 maio 07];8(3):4738-48. Disponível em: www.seer.unirio.br/index.php/cuidadofundamental/article/view/3769

19. Lopes AS, Wiese ML. A linha tênue do cuidado: prospecções da responsabilização. Soc Debate [Internet]. 2018 [acesso em 2018 set 10];24(3):63-78. Disponível em: http://revistas.ucpel.edu.br/index.php/rsd/article/view/1955/1288 
20. Jorge CF, Toldrá RC. Percepção dos cuidadores sobre a experiência de cuidar dos familiares e o relacionamento com a equipe profissional no contexto da hospitalização. Rev Ter Ocup [Internet]. 2017 [acesso em 2018 maio 11];28(3):271-80. Disponível em: https://www.revistas.usp.br/rto/article/view/117475

21. Dahdah DF, Carvalho AMP, Delsim JC, Gomes BR, Miguel VS. Grupo de familiares acompanhantes de pacientes hospitalizados: estratégia de intervenção da Terapia Ocupacional em um hospital geral. Cad Bras Ter Ocup [Internet]. 2013 [acesso em 2018 maio 07];21(02):399-404. Disponível em: www.cadernosdeterapiaocupacional.ufscar.br/index.php/cadernos/article/view/826

22. Weisser FB, Bristowe K, Jackson D. Experiences of burden, needs, rewards and resilience in family caregivers of people living with Motor Neurone Disease/Amyotrophic Lateral Sclerosis: a secondary thematic analysis of qualitative interviews. Palliat Med [Internet]. 2015 [acesso em 2018 maio 10];29(8):737-45. Disponível em: https://www.ncbi.nlm.nih.gov/pubmed/25762578

23. Sá AS, Ziviani LC, Castro-e-Silva O, Galvão CM, Mendes KDS. Necessidades de informação do cuidador familiar de candidatos ao transplante de fígado. Rev Gaúch Enferm [Internet]. 2016 [acesso em 2018 maio 09];37(01):e54650. Disponível em: http://www.scielo.br/scielo.php?pid=S1983$14472016000100408 \&$ script=sci_abstract\&tlng=pt

24. Valcarenghi RV, Lourenço LFL, Siewert JS, Alvarez AM. Produção científica da enfermagem sobre promoção de saúde, condição crônica e envelhecimento. Rev Bras Enferm [Internet]. 2015 [acesso em 2018 maio 09];68(4):705-12. Disponível em: www.scielo.br/pdf/reben/v68n4/0034-7167-reben-68-040705.pdf

\section{Autor correspondente}

E-mail: carolparruda@gmail.com

Endereço: General Osório s/n ${ }^{\circ}$

CEP: $96200-190$

\section{Contribuições de Autoria}

1 - Caroline Passos Arruda

Concepção do projeto de pesquisa; obtenção; análise; interpretação dos dados e redação.

2 - Giovana Calcagno Gomes

Planejamento do projeto de pesquisa e revisão crítica.

3 - Manoela Cunha Nicoletti

Obtenção; análise; interpretação dos dados e redação.

4 - Vanessa da Silva Tarouco

Obtenção; análise; interpretação dos dados e redação. 
Enfrentamento da internação hospitalar do paciente adulto pelo familiar cuidador | 20

5 - Cíntia Camila Santos de Souza

Obtenção; análise; interpretação dos dados e redação.

6 - Aline Ney Grehs

Obtenção; análise; interpretação dos dados e redação.

\section{Como citar este artigo}

Arruda CP, Gomes GC, Nicoletti MC, Tarouco VS, Souza CCS, Grehs AN. Enfrentamento da internação hospitalar do paciente adulto pelo familiar cuidador. Rev. Enferm. UFSM. 2019 [Acesso em: Anos Mês Dia];vol e47: P1-P19. DOI:https://doi.org/10.5902/2179769233506 